\title{
PERANCANGAN KURSI TUNGGU UNTUK IBU HAMIL DAN LANSIA PADA STASIUN KERETA SECARA ERGONOMIS
}

\author{
Adianto dan Afryan Yuda Pratama \\ Program Studi Teknik Industri, Universitas Tarumanagara \\ e-mail: afryanyuda21@gmail.com
}

\begin{abstract}
ABSTRAK
Pada saat ini fasilitas transportasi umum pada kota Tangerang sangatlah penting untuk menunjang kegiatan dalam aktifitas masyarakat, khususnya yang bekerja di kota Jakarta. Fasilitas pada stasiun seperti kursi harus diperhatikan tingkat kenyamanan penggunanya. Dari penelitian ini bertujuan untuk mengurangi keluhan fisik yang dirasakan oleh ibu hamil yang menjadi pengguna kursi tunggu pada stasiun kereta api, kursi tunggu yang dirancang dengan konsep ergonomi dan menggunakan ukuran anthropometri sesuai dengan ibu hamil. Pengumpulan data menggunakan Nordic Body Map untuk manganalisis keluhan sakit yang dirasakan oleh ibu hamil sebagai pengguna kursi tunggu di stasiun kereta. Dari Analisis REBA di hasilkan nilai 9 yang berarti level resiko tinggi. Dari data yang di kumpulkan keluhan sakit terbesar adalah di pinggang, punggung, pantat, dan kaki kanan dan kiri. Dari Morphologi chart menghasilkan 3 konsep alternatif dan terpilih 1 konsep menggunakan metode AHP.
\end{abstract}

Kata Kunci: Ergonomi, Nordic Body Map, REBA, AHP, Morphological Chart

\begin{abstract}
At the moment public transport facilities in the city of Tangerang is essential to support activities in community activities, especially those working in the city. Facilities at the station as the seat must be observed level of user comfort. This research aims to reduce the physical complaints experienced by pregnant women who are users waiting chair at the train station, waiting chair designed with the concept of ergonomics and use anthropometric measure in accordance with pregnant women. Collecting data using Nordic body map for analyzing the pains felt by pregnant women as chair users waiting at the train station. REBA analysis is derived from the value of 9, which means a high risk level. From the data collected is the biggest pains in the waist, back, buttocks, thighs, right and left legs. Morphology chart of generating three alternative concepts and elected one concept using AHP .
\end{abstract}

Keyword : Ergonomics Nordic Body Map, REBA, AHP, Morphological Chart

\section{PENDAHULUAN}

Pada saat ini fasilitas transportasi umum pada kota Tangerang sangatlah penting untuk menunjang kegiatan dalam aktifitas masyarakat, khususnya yang bekerja di kota Jakarta. Peningkatan jumlah penumpang pada stasiun kereta di Kota Tangerang juga harus di ikuti dengan penambahan fasilitas-fasilitas yang ada, salah satunya adalah kursi tunggu untuk penumpang. Kursi penumpang yang ada di Stasiun Kota Tangerang hanya berbentuk 3 batang besi yang di satukan sehingga mengurangi tingkat kenyamanan khususnya untuk para ibu hamil dan lansia.

Penelitian ini bertujuan untuk mengurangi keluhan fisik yang dirasakan oleh ibu hamil yang menjadi pengguna kursi tunggu pada stasiun kereta api, kursi tunggu yang dirancang dengan konsep ergonomi dan menggunakan ukuran anthropometri sesuai dengan ibu hamil.
Ergonomi adalah suatu ilmu tentang manusia dalam usahanya untuk meningkatkan kenyamanan di lingkungan kerjanya. Yang bertujuan menganalisis hubungan fisik antara manusia dan fasilitas. Ergonomi berkenaan pula dengan optimasi, efisiensi, kesehatan, keselamatan dan kenyamanan manusia di tempat kerja, dirumah dan tempat rekreasi. Penerapan ergonomi pada umumnya merupakan aktivitas rancang bangun (desain) ataupun rancang ulang (re-desain). Hal ini dapat meliputi perangkat keras misalnya perkakas kerja, bangku kerja, platform, kursi, pegangan alat kerja, sistem pengendali, alat peraga dan lain-lain [1]

Nordic Body Map adalah sistem pengukuran keluhan sakit pada tubuh yang dikenal dengan musculoskeletal. Sebuah sistem muskuloskeletal (sistem gerak) adalah sistem organ yang memberikan manusia kemampuan 
untuk bergerak menggunakan sistem otot dan rangka. Kuesioner Nordic Body Map merupakan kuesioner yang digunakan untuk mengetahui ketidak nyamanan pada para pekerja, kuesioner ini paling sering digunakan karena sudah terstandarisasi dan tersusun rapi.

Dalam merancang fasilitas yang berhubungan dengan manusia digunakan data antropometri dapat digunakan untuk mendesain pakaian, tempat kerja, lingkungan kerja, mesin, alat dan sarana kerja serta produk-produk untuk konsumen [2].

Untuk menganalisis risiko postur tubuh yang berhubungan dengan tugas-tugas yang dikerjakan digunakan Rapid Entire Body Assessment (REBA) yang dapat menyebabkan musculoskeletal disorder (MSD) [3].

\section{METODOLOGI PENELITIAN}

Metode penelitian mengikuti diagram alir Gambar 1.

Pada penelitian ini dilakukan pengujian kecukupan data untuk memastikan bahwa data yang dikumpulkan cukup secara obyektif, untuk uji keseragaman data yaitu untuk mendapatkan data yang seragam yang rata-ratanya diantara batas kontrol atas dan batas kontrol bawa [4].

Untuk memilih alternatif desain digunakan metode AHP (Analytical Hierarchy Process) merupakan suatu model pendukung keputusan yang dikembangkan oleh Thomas L. Saaty model pendukung keputusan ini akan menguraikan masalah mulai faktor atau kriteria yang kompleks menjadi suatu hirarki, hirarki didefinisikan sebagai suatu representasi dari sebuah permasalahan yang kompleks dalam suatu struktur multi level dimana level pertama adalah tujuan, yang diikuti level faktor, kriteria, sub kriteria hingga level terakhir dari alternatif [5].

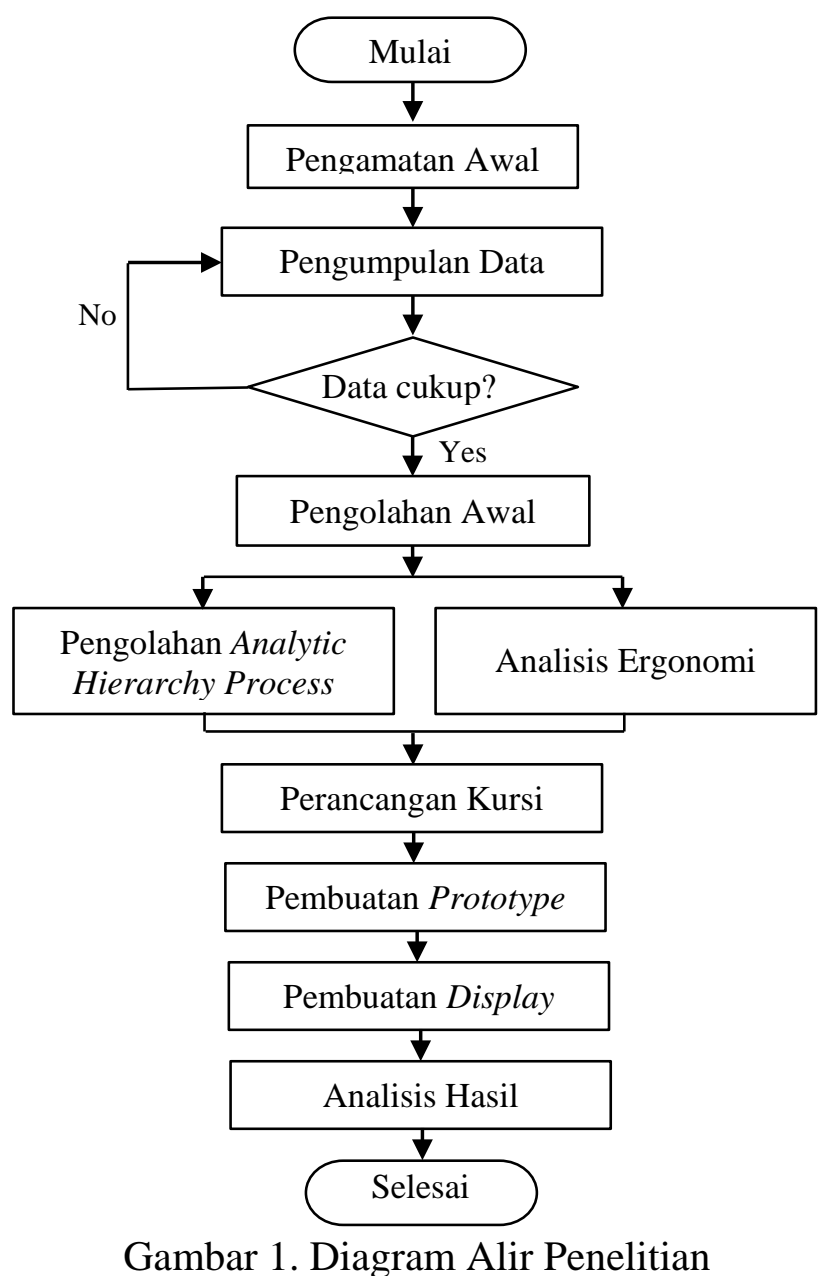

HASIL DAN PEMBAHASAN

Pengambilan data anthropometri menyesuaikan kebutuhan untuk perancangan bangku tunggu sebanyak 30 responden. Dari hasil pengolahan data statistik diperoleh nilai seperti yang ditunjukan pada Tabel 1 .

Dari hasil perhitungan didapatkan N' dari setiap kategori < $30\left(\mathrm{~N}^{\prime}<\mathrm{N}\right)$ maka dapat disimpulkan data pengguna kursi tunggu

Tabel 3. Data Statistik Pengukuran Anthropometri.

\begin{tabular}{cccccccc} 
& $\begin{array}{c}\text { Tinggi } \\
\text { badan } \\
\text { posisi } \\
\text { tegak }\end{array}$ & $\begin{array}{c}\text { Tinggi } \\
\text { Sandaran } \\
\text { Punggung }\end{array}$ & $\begin{array}{c}\text { Jarak dari } \\
\text { lipat lutut } \\
\text { (polipteal) } \\
\text { ke pantat }\end{array}$ & $\begin{array}{c}\text { Tinggi } \\
\text { lipat lutut }\end{array}$ & $\begin{array}{c}\text { Lebar } \\
\text { bahu }\end{array}$ & $\begin{array}{c}\text { Lebar } \\
\text { Panggul }\end{array}$ & $\begin{array}{c}\text { Tinggi siku } \\
\text { pada posisi } \\
\text { duduk }\end{array}$ \\
\hline$\Sigma \mathrm{X}$ & 4650 & 1712 & 1512 & 1147 & 1198 & 1246 & 1353 \\
$\Sigma \mathrm{X}^{2}$ & 721428 & 98210 & 76578 & 44267 & 48238 & 52466 & 62063 \\
Standar Deviasi & 4,84 & 1,31 & 2,24 & 3,78 & 3,70 & 4,97 & 1,47 \\
$\mathbf{N}^{\prime}$ & 1,51 & 1,30 & 8,36 & 15,1 & 13,3 & 22,12 & 17,89 \\
$\bar{X}$ & 155 & 45,27 & 30,47 & 38,23 & 39,93 & 41,53 & 13,67 \\
\hline
\end{tabular}


distasiun kereta api kota Tangerang cukup untuk diolah dalam penelitian ini. Kursi yang akan dirancang berdasarkan anthropometri dengan presentil 5\% dengan perhitungan.

Tabel 2. Ukuran dengan Presentil 5\%

\begin{tabular}{lcc}
\hline \multicolumn{1}{c}{ Data Anthropometri } & $\bar{X}$ & $\begin{array}{c}\text { Persentil } \\
5 \%\end{array}$ \\
\hline Tinggi lipat lutut & 38,23 & 32,02 \\
Tinggi siku pada posisi duduk & 13,60 & 11,20 \\
Tinggi Sandaran Punggung & 45,27 & 47,50 \\
Jarak dari lipat lutut (polipteal) & 30,44 & 34,15 \\
ke pantat & & \\
Lebar bahu & 39,93 & 46,02 \\
Lebar Panggul & 41,53 & 49,70 \\
\hline
\end{tabular}

Tabel 3. Ranking Nordic Body Map

\begin{tabular}{clcc}
\hline No & \multicolumn{1}{c}{ Keluhan Sakit } & $\begin{array}{c}\text { Tidak } \\
\text { Sakit }\end{array}$ & Sakit \\
\hline 1 & Sakit pada pinggang & 1 & 29 \\
2 & Sakit pada punggung & 2 & 28 \\
3 & Sakit pada pantat (buttock) & 7 & 23 \\
4 & Sakit pada kaki kanan & 11 & 19 \\
5 & Sakit pada betis kanan & 12 & 18 \\
6 & Sakit pada kaki kiri & 12 & 18 \\
7 & Sakit pada pantat (bottom) & 12 & 18 \\
8 & Sakit pada betis kiri & 14 & 16 \\
\hline
\end{tabular}

Identifikasi keluhan pada bagian tubuh dilakukan dengan cara pengisian kuesioner Nordic body map. Berikut adalah ranking keluhan fisik yang dirasakan pada penumpang
30 orang ibu hamil yang menjadi respondent pada saat duduk dikursi tunggu di Stasiun kereta api Kota Tangerang. Dapat dilihat pada Tabel 3.

Setelah melakukan analisis keluhan sakit dengan Nordic Body Map, maka selanjutnya akan dianalisis tentang posisi duduk ibu hamil dengan menggunakan analisis Rapid Entire Body Assesment (REBA). Berikut adalah gambar analisis REBA posisi duduk ibu hamil.

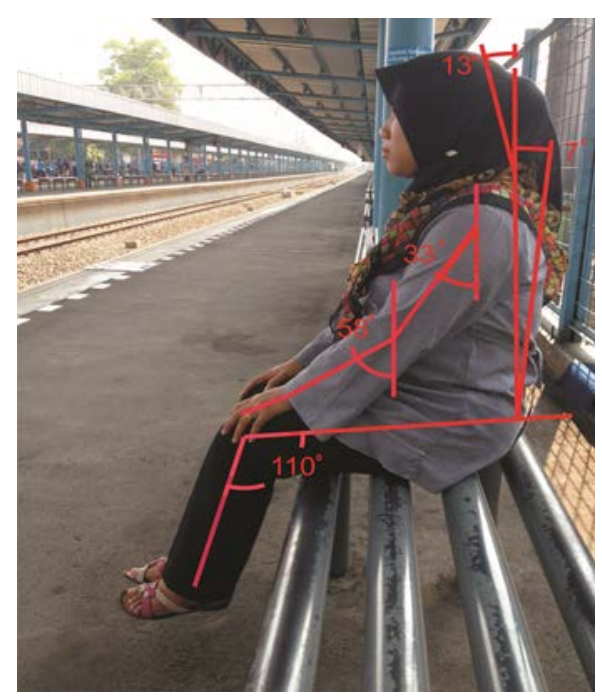

Gambar 2. Posisi Duduk Ibu Hamil

Dari analisis foto di atas mendapatkan sudut dari posisi tubuh saat duduk dan mendapatkan hasil skor reba 9 dengan level

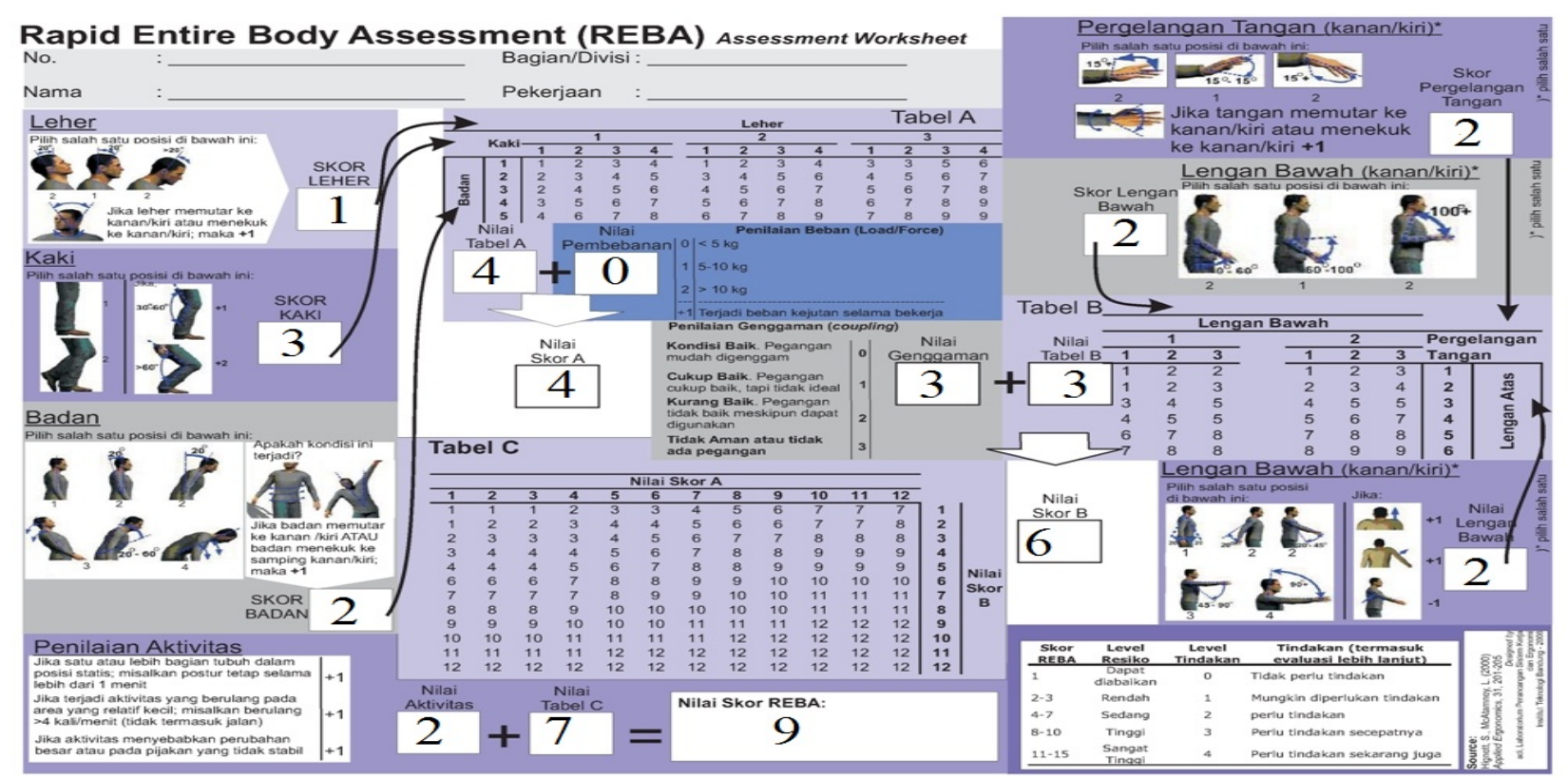

Gambar 3. Worksheet REBA. 
Tabel 4. Morfologi Chart

\begin{tabular}{|c|c|c|c|c|}
\hline \multirow{2}{*}{ No } & \multirow{2}{*}{ Karakteristik } & \multicolumn{3}{|c|}{ Alternatif } \\
\hline & & 1 & 2 & 3 \\
\hline 1 & Material Kerangka & Best & Alumunium & Kayu \\
\hline 2 & $\begin{array}{l}\text { Fungsi Sandaran } \\
\text { Kaki dan Sandaran } \\
\text { tangan }\end{array}$ & Naik-tureriा & & \\
\hline 3 & $\begin{array}{l}\text { Material Senderan } \\
\text { dan Dudukan }\end{array}$ & Kayu & & Alumunium \\
\hline 4 & Ergonomi & $\begin{array}{c}\text { Anthropometri ses } \\
\text { dengan data ibu } \\
\text { hamil }\end{array}$ & $\begin{array}{l}\text { Anthropometi } \\
\text { sesuai orang } \\
\text { dengal asia }\end{array}$ & $\begin{array}{c}\text { Anthropometri } \\
\text { sesuai dengan orang } \\
\text { indonesia }\end{array}$ \\
\hline & & 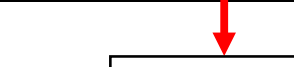 & & $\checkmark$ \\
\hline & & Konsep 1 & Konsep 2 & Konsep 3 \\
\hline
\end{tabular}

resiko Tinggi dan perlu tindakan secepatnya agar mengurangi keluhan sakit yg dirasakan.

Dari Tabel 3 Ranking Nordic Body Map dan analisis REBA pada Tabel 9 sakit pada pinggang dan punggung disebabkan kursi tidak memiliki sandaran, sakit pada pantat disebabkan dudukan kursi tidak rata, sakit pada kaki, betis kanan dan kiri disebabkan karena posisi kaki menggantung. Sehingga untuk alternatif disain kursi tunggu untuk ibu hamil adalah memiliki sandaran, memiliki penyanggah tangan, memiliki penyanggah kaki dan ukuran tinggi kursi harus sesuai dengan tungkai kaki.

Maka untuk mengurangi keluhan yang dirasakan ibu hamil terhadap kursi tunggu yang ada di Stasiun Kota Tangerang diperoleh 3 alternatif disain dengan menggunakan Morphologi Chart. Morphologi Chart dibuat untuk membangkitkan alternatif solusi rancangan sekaligus untuk mencari potensi solusi solusi yang baru [5]. Dari Penyaringan alternatif didapatkan 3 konsep rancangan yang dapat dipertimbangkan.

Gambar dari setiap alternatif disain produk dapat dilihat pada Gambar 3, Gambar 4, dan Gambar 5.

Pemilihan konsep dilakukan mengunakan metode AHP dengan melibatkan ibu hamil, bidan dan pembuat kursi sebagai responden. Berikut adalah gambar struktur hierarki AHP dapat dilihat pada Gambar 6.

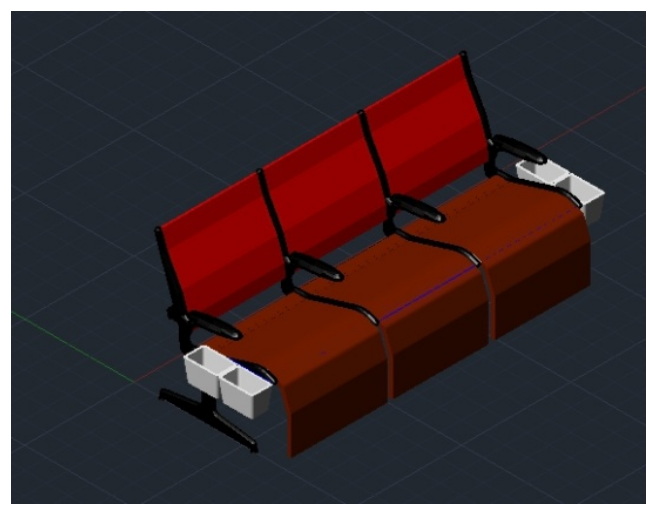

Gambar 3. Konsep Bangku 1

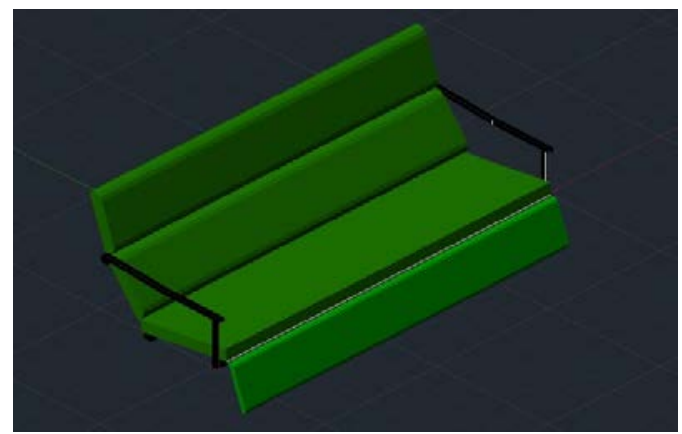

Gambar 4. Konsep Bangku 2

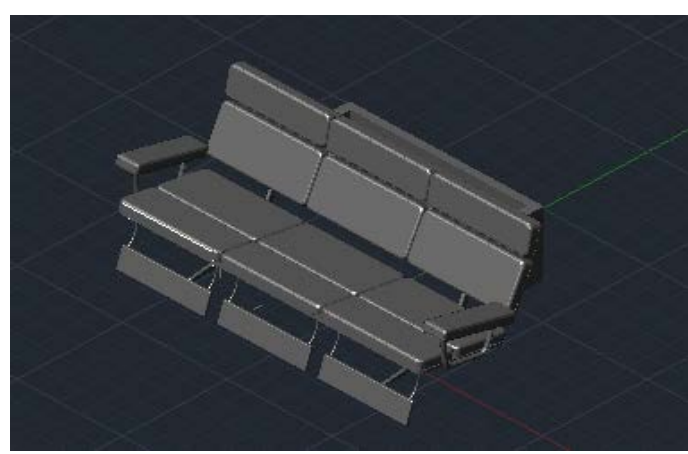

Gambar 5. Konsep Bangku 3 


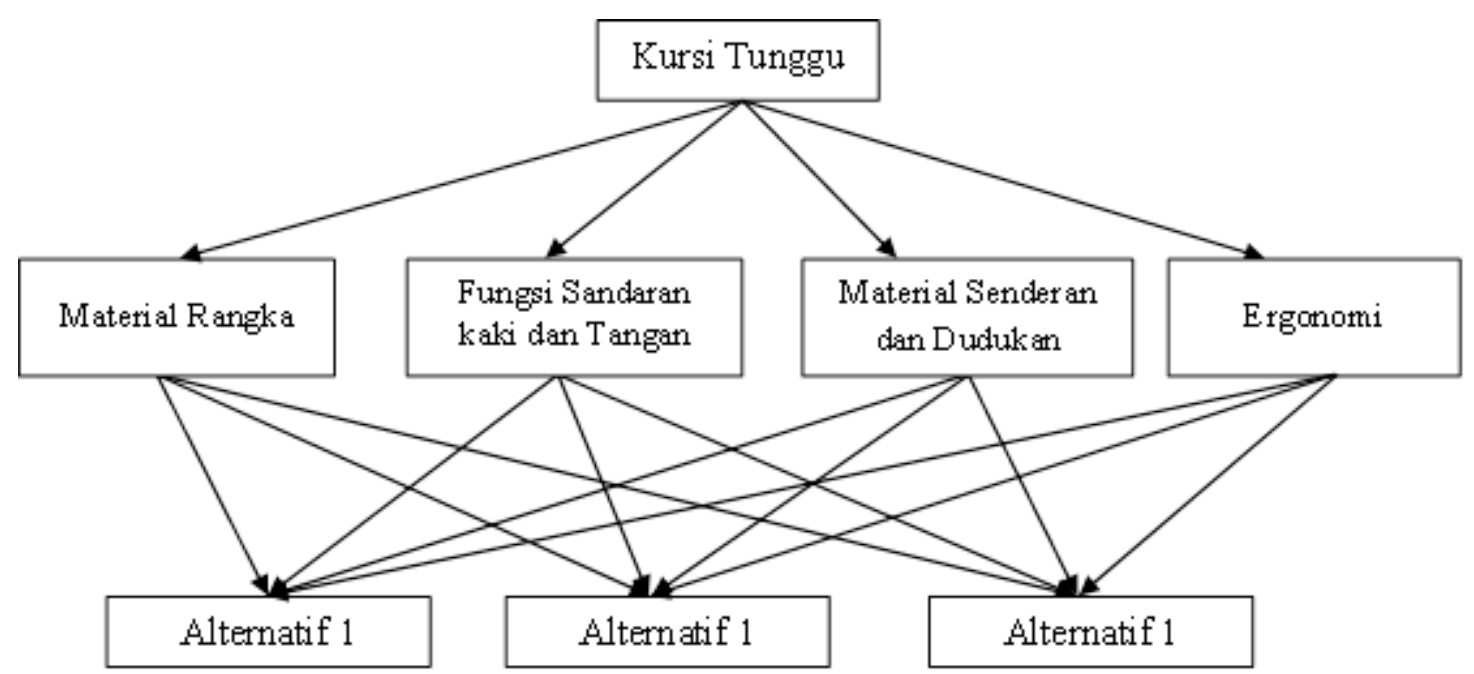

Gambar 6. Struktur Hierarchy AHP.

Tabel 5. Hasil Penilaian dengan Menggunakan AHP.

\begin{tabular}{|c|c|c|c|c|c|c|c|c|c|c|c|}
\hline \multirow[b]{2}{*}{ No } & \multicolumn{2}{|c|}{ Kriteria Evaluasi } & \multicolumn{3}{|c|}{ Alternatif 1} & \multicolumn{3}{|c|}{ Alternatif 2} & \multicolumn{3}{|c|}{ Alternatif 3} \\
\hline & Tujuan & $\mathrm{Wt}$ & $\begin{array}{c}\text { Nilai } \\
\text { v. }\end{array}$ & Ket & Wt.V & $\begin{array}{c}\text { Nilai } \\
\text { v. }\end{array}$ & Ket & Wt.V & $\begin{array}{c}\text { Nilai } \\
\text { v. }\end{array}$ & Ket & Wt.V \\
\hline 1 & $\begin{array}{c}\text { Material } \\
\text { Kerangka }\end{array}$ & 0,25 & 4,33 & Baik & 1,08 & 2,66 & $\begin{array}{c}\text { Kurang } \\
\text { Baik }\end{array}$ & 0,66 & 2,66 & $\begin{array}{c}\text { Kurang } \\
\text { Baik }\end{array}$ & 0,66 \\
\hline 2 & $\begin{array}{c}\text { Material } \\
\text { Senderan } \\
\text { dan } \\
\text { Dudukan }\end{array}$ & 0,17 & 3,33 & $\begin{array}{l}\text { Cukup } \\
\text { baik }\end{array}$ & 0,57 & 2,33 & $\begin{array}{c}\text { Kurang } \\
\text { Baik }\end{array}$ & 0,40 & 4,33 & Baik & 0,74 \\
\hline 3 & $\begin{array}{c}\text { Fungsi } \\
\text { Sandaran } \\
\text { Kaki dan } \\
\text { Sandaran } \\
\text { tangan } \\
\end{array}$ & 0,20 & 3,33 & $\begin{array}{l}\text { Cukup } \\
\text { Baik }\end{array}$ & 0,66 & 3 & $\begin{array}{l}\text { Cukup } \\
\text { baik }\end{array}$ & 0,59 & 2,66 & $\begin{array}{c}\text { Kurang } \\
\text { Baik }\end{array}$ & 0,53 \\
\hline 4 & Ergonomi & 0,38 & 4,33 & Baik & 1,66 & 3,33 & $\begin{array}{l}\text { Cukup } \\
\text { Baik }\end{array}$ & 1,27 & 3,33 & $\begin{array}{c}\text { Cukup } \\
\text { baik }\end{array}$ & 1,27 \\
\hline \multicolumn{5}{|c|}{ Total } & 3,98 & & & 2,93 & & & 3,21 \\
\hline
\end{tabular}

Nilai (v) didapat dari rata-rata hasil penilaian ahli berdasarkan kuesioner nilai alternatif. Setelah dilakukan perbandingan nilai atribut maka alternatif yang tepilih adalah alternatif 1 karena nilai atributnya paling besar di antara alternatif lainnya.

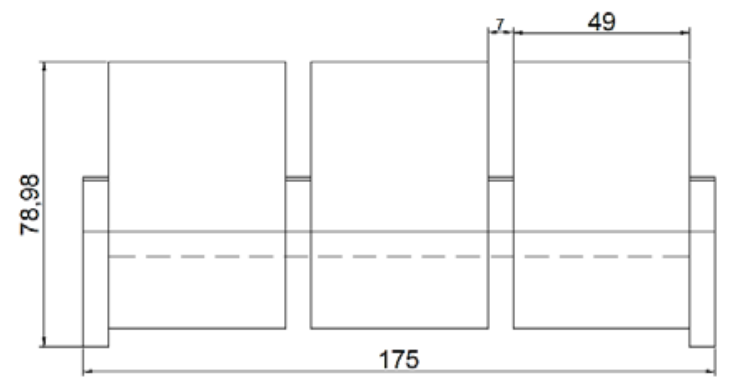

Gambar 7 Tampak Depan Prototype
Dari hasil pemilihan konsep-konsep dari metode AHP, konsep 1 terpilih sebagai konsep yang akan dibuat, dalam membuat kursi tunggu diperlukan dimensi kursi yang telah disesuaikan dengan anthropometri Ibu hamil. Beikut ini adalah dimensi kursi dari tampak depan, tampak atas, tampak samping dan gambar 3D.

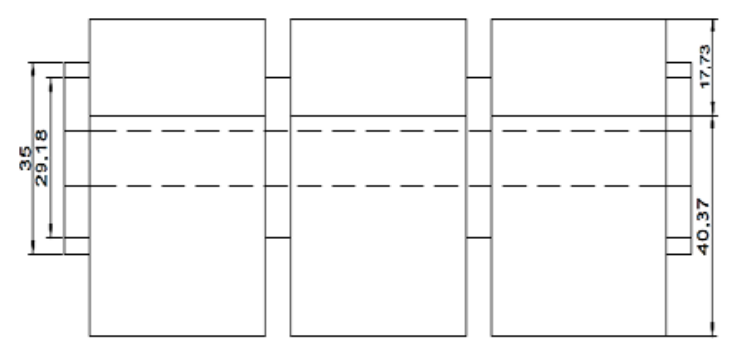

Gambar 8. Tampak Atas Prototype 


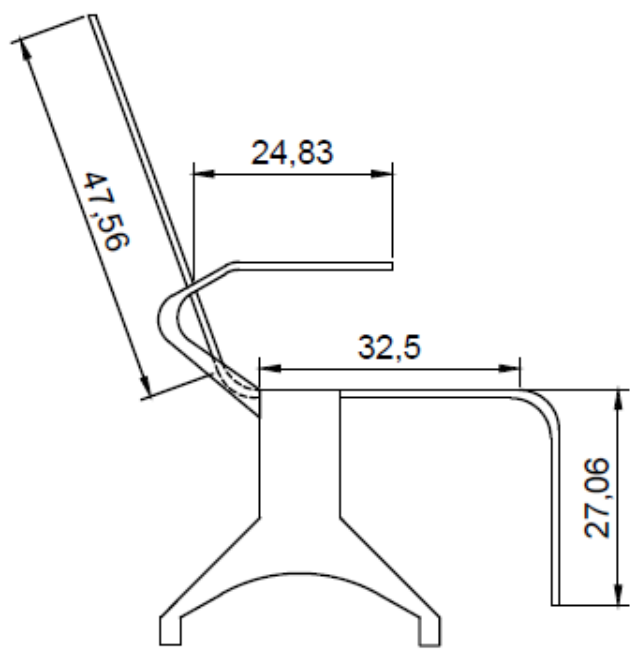

Gambar 9. Tampak Samping Prototype

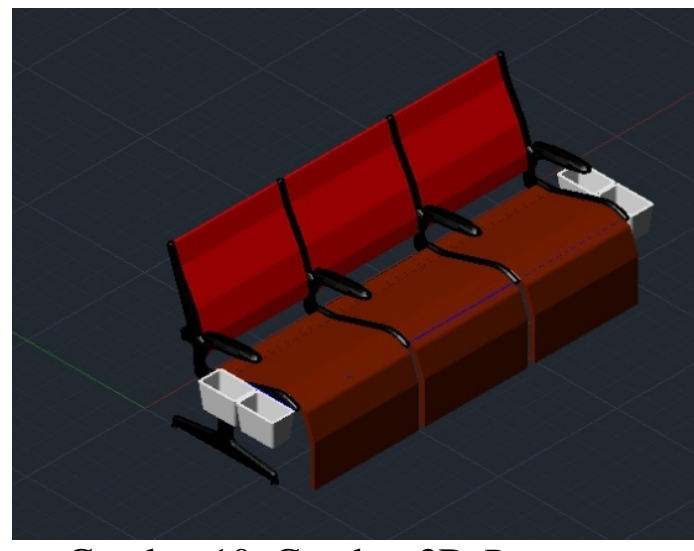

Gambar 10. Gambar 3D Prototype

Disain kursi yang dihasilkan diharapkan dapat mengurangi keluhan yang dirasakan oleh ibu hamil di Stasiun Kereta Api Kota Tangerang.

\section{KESIMPULAN}

Berdasarkan hasil penelitian terdapat keluhan sakit pada penggunaan kursi tunggu di stasiun kereta api. Hal ini disebabkan karena material dan bentuk kursi yang tidak sesuai.
Berdasarkan hasil Nordic Body Map keluhan tertinggi terdapat di pinggang, punggung, kaki kanan dan kiri serta betis kanan dan kiri dengan nilai REBA 9 menunjukan level resiko tinggi dan perlu tindakan secepatnya agar mengurangi keluhan sakit yg dirasakan. Pemilihan konsep dengan menggunakan metode AHP. Sehingga alternatif disain kursi yang terpilih adalah disain kursi yang memiliki sandaran, memiliki penyanggah tangan, memiliki penyanggah kaki dan ukuran tinggi kursi harus sesuai dengan tungkai kaki.

\section{DAFTAR PUSTAKA}

[1] Nurmianto, eko. 1998. Ergonomi Konsep Dasar Dan Aplikasinya. Surabaya : Guna Widya.

[2] Pulat, B.M. 1992. Fundamentals of Industrial Ergonomics. Hall International. Englewood Cliffs. New Jersey. USA.

[3] Hignett, S. and L. McAtamney, 2000. Rapid Entire Body Assessment (REBA). Applied Ergonom.

[4] Sutalaksana Iftikar Z, Angga Ruhana, Tjakraatmadja jann H. 2006. Teknik Perancangan Sistem Kerja. Bandung : ITB

[5] Saaty, Thomas L. 1991. Proses Hirarki Analitik Untuk Pengambilan Keputusan Dalam Situasi Yang Kompleks. Jakarta : PT. Dharma Aksaa Perkasa 